\title{
Identification of Degradant Products of Saroglitazar by UPLC Tandem Mass Spectroscopy and Attenuated Total Reflection FTIR Techniques
}

\author{
T N V Ganesh Kumar ${ }^{1, \star}$, S Vidyadhara1, Niteen Ashok Narkhede ${ }^{2}$, N Yamini Sai Silpa ${ }^{1}$, \\ M Rajya Lakshmi ${ }^{1}$ \\ ${ }^{1}$ Department of Pharmaceutical Analysis, Chebrolu Hanumaiah Institute of Pharmaceutical Sciences, Guntur, Andhra Pradesh, INDIA. \\ ${ }^{2}$ Council for Scientific and Industrial Research (CSIR)-Indian Institute Integrative Medicine, Mumbai, Maharashtra, INDIA.
}

\begin{abstract}
Saroglitazar is a newly approved oral hypoglycemic drug by FDA. Although the drug entered the market, there are no reports on its degradation products till date. To identify the degradation products of saroglitazar during the stability studies, a RP-HPLC method was developed and validated as per $\mathrm{ICH}$ guidelines. The samples were eluted using acetonitrile and phosphate buffer $(\mathrm{pH} 7.4,50: 50 \mathrm{v} / \mathrm{v})$ as a mobile phase over Kromasil $100-5 C_{18}(250 \times 4.6 \mathrm{~mm}, 5 \mu \mathrm{m})$ column. The analytes were monitored by UV detector at $294 \mathrm{~nm}$ with isocratic mode of elution at a flow rate of $1.0 \mathrm{~mL} / \mathrm{min}$. The stability studies were conducted under stressed conditions of acidic, basic, neutral (peroxide), photolytic studies at room temperature and thermal at $60^{\circ} \mathrm{C}$ for 48 hours. The stressed samples were analyzed for their degradation products by RP-HPLC. The degradant products obtained were characterized using UPLC with tandem mass spectroscopy (LC/MS/MS) and FTIR. Major degradation products were observed with $\mathrm{m} / \mathrm{z}$ at 365, 247 and 294 . The drug is found to be comparatively stable under photo and thermal stress. Peroxide stress has degraded the drug completely. The drug has to be stored away from oxidation during transport and storage.
\end{abstract}

Key words: Saroglitazar, Degradation products, Reverse phase high performance liquid chromatography, Mass spectroscopy, Infra-red spectroscopy.

\section{INTRODUCTION}

Saroglitazar (SGR) is a new chemical entity used for the treatment of type 2 diabetes mellitus. It can be used to treat the people suffering from dyslipidemia and hypertriglyceridemia, where statin therapy is not useful. ${ }^{1,2}$ Chemically, it is (2S) - 2- Ethoxy - 3- [4- (2- \{2-methyl-5- [4 (methylsulfanyl) phenyl] -1 pyrrol-1-yl $\}$ ethoxy) phenyl] propanoic acid (Figure 1). ${ }^{1,3,4}$ SGR shows the dual effect on peroxisome proliferator activated receptor (PPAR) as an agonist at the subtypes $\alpha$ and $\gamma$. Agonist action at PPAR $\alpha$ and $\operatorname{PPAR} \gamma$, decreases the high blood triglycerides and enhances the insulin resistance respectively and accordingly lowers blood sugar level., 5 The earlier reports on SGR revealed that because of its effect as insulin sensitizer, there has less possibility for hypoglycemic shock and no considerable serious adverse effects were observed. ${ }^{6-8}$ SGR has not revealed any of the adverse effects like edema and weight gain that are usually identified with other anti diabetic drugs. ${ }^{9-10}$ Although the drug is available in the market, it was observed that only HPLC and HPTLC studies for its estimation in formulations were reported. ${ }^{11-12}$ But there are no reports on its degradation products during the course of transport and stressed conditions of storage. The formation of degraded products may raise a serious issue in terms of its shelf life as well as their toxicity profile. The reported clinical studies mentioned that there was no much toxicity
Submission Date: 25-01-2018; Revision Date: 13-04-2018; Accepted Date: 17-05-2018

DOI: 10.5530/ijper.52.4.74 Correspondence:

Dr. T N V Ganesh Kumar, Associate Professor,

Department of Pharmaceutical Analysis, Chebrolu Hanumaiah Institute of Pharmaceutical Sciences, Guntur, Andhra Pradesh, INDIA.

Phone: +(91)-8985283248 E-mail: ganeshtnv@gmail. com

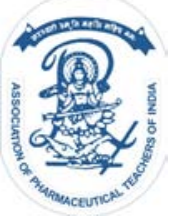

www.ijper.org 


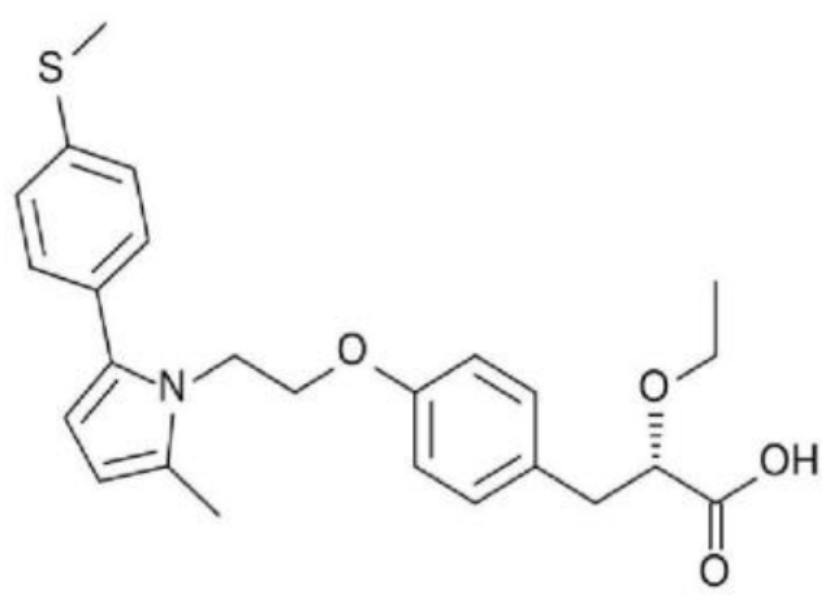

Figure 1: Structure of saroglitazar.

for the drug, ${ }^{5}$ but there might be a chance that the storage conditions may cause the drug molecule to degrade and which may be toxic to the body. Hence it is necessary to identify the degraded products forming during the stressed conditions and their correlation with the starting reactants during SGR synthesis. The toxicity profile has to be established if the degraded products formed are different than expected and appropriate quality control measures have to be taken during the manufacturing of the drug substances, during the shipment, distribution and storage. Thus the current study was focused on to perform the stability indicating degradation studies for SGR and identify the degraded products by RP-HPLC and characterize by FTIR and LCMS.

\section{MATERIALS AND METHODS}

\section{Chemicals}

HPLC grade acetonitrile (Lichrosolv®, Merck life sciences, Pvt. Ltd, Mumbai, India), HPLC grade water (Lichrosolv®, Merck life sciences, Pvt. Ltd. Mumbai, India), formic acid and potassium dihydrogen o-phosphate (Thermo fisher scientific Pvt. Ltd. Mumbai, India), sodium hydroxide, hydrochloric acid, and hydrogen peroxide (S D Fine-chem. Ltd. Mumbai, India) were used for the study. Saroglitazar pure drug and its tablet formulation were obtained from Cadila pharmaceutical limited, Ahmedabad, India.

\section{Apparatus}

The HPLC system (Agilent technologies, compact LC-G4286A made in Germany) with variable wavelength UV-detector, reversed phase Kromasil ${ }^{\circledR} 100-5 C_{18}$ $(250 \times 4.6 \mathrm{~mm}, 5 \mu \mathrm{m}$ particle size) column were used for chromatographic separation. The chromatographic and integrated data were recorded using Ezichrome
Elite compact software in computed system (Version: 3.30B, Sr. no: 08051601100 , scientific software. Inc.). For LCMS studies, UPLC system consisting of gradient mode pump with column Acquity UPLC@B,BH C18 $(1.7 \mu \mathrm{m}, 2.1 \times 100 \mathrm{~mm})$ and Photo Diode Array (PDA) detector range 200-400 $\mathrm{nm}$ were used. The mass spectrum with ESI mode of ionization was used for the study (LC/MS/MS (Waters ACQUITY. Model: XEVOTQD). Bruker FTIR Model: Alpha, containing fixed thickness liquid cell- sodium chloride rectangular crystal with path length spacer of $0.1 \mathrm{~mm}$ was used for functional group analysis of samples.

\section{RP-HPLC Conditions}

Chromatographic separation was achieved on Kromasil ${ }^{\circledR}$ $100-5 C_{18}$ using a mobile phase consisting of phosphate buffer adjusted to $\mathrm{pH} 7.4$ and acetonitrile in the ratio of 50:50 v/v, under isocratic mode of elution. The mobile phase was prepared and filtered through membrane filter $(0.45 \mu \mathrm{m})$ and sonicated for $30 \mathrm{~min}$ prior to use. Flow rate of $1 \mathrm{~mL} / \mathrm{min}$ was maintained at room temperature with a run time of $25 \mathrm{~min}$. An injection volume of $20 \mu \mathrm{L}$ is used and the detection wavelength was set at $294 \mathrm{~nm}$.

\section{UPLC/MS/MS Conditions}

Chromatographic separation was achieved on ACQUITY UPLC@BEH C18 1.7 $\mu \mathrm{m}, 2.1 \times 100 \mathrm{~mm}$ column, using the gradient mobile phase consisting of A (water with $0.1 \%$ formic acid) and B (Acetonitrile). A flow rate of $0.4 \mathrm{~mL} / \mathrm{min}$ and column temperature of $40^{\circ} \mathrm{C}$ was maintained for the entire study and the eluted components were detected using PDA at the range of $200-400 \mathrm{~nm}$. The products were ionized by electro spray ionization (ESI) mode for their mass data.

\section{FTIR Conditions}

The samples were analyzed using Bruker FTIR Model: Alpha, having liquid cell $\mathrm{NaCl}$ crystal with path length of $0.1 \mathrm{~mm}$. The degradation products were extracted from the stressed samples using chloroform before analysis. The samples were measured for their transmission range of 600 to $4000 \mathrm{~cm}^{-1}$. Total 20 scans per sample were performed for better resolution of spectra.

\section{Sample Preparation}

The standard and test samples were prepared by dissolving each weighed amount of $10 \mathrm{mg}$ SGR in $10 \mathrm{~mL}$ methanol and sonicated for $10 \mathrm{~min}$. The obtained $1 \mathrm{mg} / \mathrm{mL}$ concentration solutions were used for further studies. 


\section{Sample Preparation for Stability Studies}

For the degradation studies, 48 hours of stressed conditions were performed for the drug sample. Except thermal, photolytic and peroxide stressed samples, the samples of acid and base hydrolysis were neutralized with sodium hydroxide and hydrochloric acid respectively.

\section{Degradation studies ${ }^{13-15}$ \\ Acid degradation}

Weighed, $2 \mathrm{mg}$ of SGR and treated with $5 \mathrm{~mL}$ of $0.1 \mathrm{~N}$ $\mathrm{HCl}$ at room temperature for $48 \mathrm{hr}$. After $48 \mathrm{hr}$, the stressed sample was neutralized with $0.1 \mathrm{~N} \mathrm{NaOH}$ and diluted with methanol to get $1000 \mu \mathrm{g} / \mathrm{mL}$. The solution was filtered through $0.45 \mu \mathrm{m}$ membrane before analysis.

\section{Base degradation}

Weighed, $2 \mathrm{mg}$ of SGR and treated with $5 \mathrm{~mL}$ of $0.1 \mathrm{~N}$ $\mathrm{NaOH}$ at room temperature for $48 \mathrm{hr}$. The stressed sample was further neutralized with $0.1 \mathrm{~N} \mathrm{HCl}$ and diluted with methanol to get $1000 \mu \mathrm{g} / \mathrm{mL}$. The solution was filtered through $0.45 \mu \mathrm{m}$ membrane before analysis.

\section{Hydrogen peroxide degradation}

Weighed, $2 \mathrm{mg}$ of SGR and treated with $5 \mathrm{~mL}$ of 3 $\%$ hydrogen peroxide at room temperature for $48 \mathrm{~h}$. The stressed sample was diluted with methanol to get $1000 \mu \mathrm{g} / \mathrm{mL}$. The solution was filtered through $0.45 \mu \mathrm{m}$ membrane before analysis.

\section{Photolytic degradation}

The photolytic degradation was carried under the influence of UV light on the stability of SGR by exposing 2 $\mathrm{mg}$ of the sample at $365 \mathrm{~nm}$ for 48 hours. The stressed sample was diluted with methanol.

\section{Thermolysis degradation}

The effect of temperature was studied by heating the sample at $60^{\circ} \mathrm{C}$ for $48 \mathrm{~h}$ in refluxing apparatus. The stressed sample was diluted with methanol to get $1000 \mu \mathrm{g} / \mathrm{mL}$ concentration. The solution is filtered through $0.45 \mu \mathrm{m}$ membrane before analysis.

\section{Validation Studies}

The validation studies of SGR were carried as per ICH guidelines. ${ }^{13-15}$

\section{System suitability}

The system suitability of SGR was performed by taking six injections $(\mathrm{n}=6)$ of pure sample $(250 \mu \mathrm{g} / \mathrm{mL})$ and calculated the \% RSD. The system was suitable for the analysis of SGR data of tailing factor and peak resolution results were within the limits.

\section{Linearity}

The linearity of SGR was performed from the standard concentrations in the range of $50-250 \mu \mathrm{g} / \mathrm{mL}$. The calibration curve of peak height versus concentration was plotted and correlation coefficient and regression line equation were determined.

\section{Precision}

The precision of the method was determined by injecting six $(n=6)$ injections of SGR pure sample $(200 \mu \mathrm{g} / \mathrm{mL})$ and $\%$ RSD was calculated. The obtained RSD was within the range $(\leq 2)$ and it was observed that the developed method was reproducible.

\section{Accuracy}

The accuracy study of the method was performed by adding known amount of different ranges of pure drug to the standard test concentration. The recovery was performed at three levels with 50, 100 and $150 \%$ of SGR standard concentration. The three samples were prepared for each recovery level and $\%$ recoveries were calculated.

\section{Limits of Detection (LOD) and Limit of Quantification (LOQ)}

The LOD and LOQ are the lowest level and lowest concentration of the analyte respectively in a sample that would yield signal-to-noise ratios of 3.3 for LOD and 10 for LOQ. These were determined from the standard deviation of the peak response and the slope of the calibration curve.

\section{RESULTS AND DISCUSSIONS}

\section{Method development and optimization of chromatographic (RPHPLC) conditions}

Initial trials were made using water and methanol in the ratio of $50: 50 \mathrm{v} / \mathrm{v}$ as mobile phase on Kromasil ${ }^{\circledR}$ 100- $5 \mathrm{C}_{18}$ column with flow rate of $1 \mathrm{~mL} / \mathrm{min}$, and found the peak with high tailing. Phosphate buffer ( $\mathrm{pH}$ 7.4) and acetonitrile in the ratio of $50: 50 \mathrm{v} / \mathrm{v}$ with flow rate of $1.2 \mathrm{~mL} / \mathrm{min}$ gave sharp peaks with no tailing. Though the retention time (Rt) of drug was very less, peaks were eluted with better resolution and intensity at high concentration $(1000 \mu \mathrm{g} / \mathrm{mL})$ of drug. As the aim of current study was to identify the degradation products, longer Rt was required. Hence, the flow rate was decreased to $1 \mathrm{~mL} / \mathrm{min}$ with same mobile phase, which gave a longer Rt of $8.2 \pm 0.1$ minutes, without disturbing the peak properties. The system suitability was performed and the results were found to be within the limits (Table 1). Linearity was observed in the concentration range of $50-250 \mu \mathrm{g} / \mathrm{mL}$ with regression 
Table 1: System suitability of Saroglitazar.

\begin{tabular}{|c|c|c|}
\hline $\begin{array}{c}\text { Concentration } \\
(\boldsymbol{\mu} \mathbf{g} / \mathrm{mL})\end{array}$ & Peak Height (mAu) & $\begin{array}{c}\text { Retention time } \\
(\mathbf{m i n})\end{array}$ \\
\hline 250 & 128979035 & 8.21 \\
\hline 250 & 128979038 & 8.20 \\
\hline 250 & 128979040 & 8.20 \\
\hline 250 & 128979038 & 8.20 \\
\hline 250 & 128979040 & 8.20 \\
\hline 250 & 128979035 & 8.19 \\
\hline Average & 128979038 & \\
\hline $\begin{array}{l}\text { Standard } \\
\text { deviation }\end{array}$ & 2.2509 & \\
\hline \% RSD & 0.00174 & \\
\hline \multicolumn{2}{|l}{} \\
\hline
\end{tabular}

\begin{tabular}{|c|c|c|}
\hline \multicolumn{3}{|c|}{ Table 2: Linearity of Saroglitazar. } \\
\hline $\begin{array}{c}\text { Concentration } \\
(\mu \mathrm{g} / \mathrm{mL})\end{array}$ & Peak Area (mAu) & $\begin{array}{c}\text { Retention time } \\
(\mathbf{m i n})\end{array}$ \\
\hline 50 & 28476322 & 8.25 \\
\hline 100 & 47619053 & 8.29 \\
\hline 150 & 77293815 & 8.25 \\
\hline 200 & 102039811 & 8.23 \\
\hline 250 & 128979035 & 8.21 \\
\hline
\end{tabular}

Table 3: Precision results of Saroglitazar.

\begin{tabular}{|c|c|c|}
\hline $\begin{array}{c}\text { Concentration } \\
(\boldsymbol{\mu g} / \mathbf{m L})\end{array}$ & $\begin{array}{c}\text { Peak Height } \\
(\mathbf{m A u})\end{array}$ & $\begin{array}{c}\text { Retention time } \\
(\mathbf{m i n})\end{array}$ \\
\hline 200 & 102039811 & 8.21 \\
\hline 200 & 102039809 & 8.22 \\
\hline 200 & 102039815 & 8.22 \\
\hline 200 & 102039811 & 8.21 \\
\hline 200 & 102039810 & 8.22 \\
\hline 200 & 102039808 & 8.32 \\
\hline Average & 102039810 & \\
\hline Standard deviation & 2.4221 & \\
\hline \%RSD & $0.000213 \%$ & \\
\hline
\end{tabular}

coefficient of 0.998 and was summarized in Table 2. The $\%$ RSD for system suitability of SGR with six injections ( $\mathrm{n}=6$ ) was found to be $1.122 \%$, which is within the limits. The $\%$ RSD for intraday precision was found to be $0.213 \%$ and within the limits (Table 3). The accuracy of the method with recovery level 50, 100 and $150 \%$ was found to be 100.18, 99.69 and 99.89 $\%$ respectively were tabulated in Table 4 . The LOD and LOQ for SGR were observed at1.7732 $\mu \mathrm{g} / \mathrm{mL}$ and $5.3735 \mu \mathrm{g} / \mathrm{mL}$ respectively were tabulated in Table 5 . The results were within the limits of guidelines.

\section{Stability studies by RP-HPLC}

The stressed samples of SGR were analyzed by RP-HPLC. Significant degradation product peaks were observed in acidic, basic, neutral (hydrogen peroxide), photolytic and thermolysis conditions at $294 \mathrm{~nm}$. To know if any other products are present, samples were also analyzed at $254 \mathrm{~nm}$. Peroxide stress sample has shown peaks at both 294 and $254 \mathrm{~nm}$, whereas in other conditions, peaks were observed only at $294 \mathrm{~nm}$. From the data it is observed that peaks other than SGR have absorption maximum at 294 and $254 \mathrm{~nm}$ with absorbance of 0.73 and 0.56 respectively in UV. The resultant HPLC chromatograms of stressed samples were shown in Figure 2 and 3. The peak intensities and retention times of degraded product peaks during stress conditions were tabulated in Table 6 . The drug shows 100\% degradation under oxidation stress where as good stability under photolysis $(1.28 \%)$ and thermal $(5.69 \%)$ stress. A major instability is also observed in acid (85.18\%) and base (71.95\%) stress. The percentage degradation was tabulated in Table 7. The samples were analyzed using UPLC-MS/MS for identifying the molecular weights of degraded products and to predict their structures. The UPLC data for acid, base, hydrogen peroxide were depicted in Figure 4 and photolytic and thermally stressed samples were depicted in Figure 5. The mass spectral data of acid, base, hydrogen peroxide, U.V. and thermal were shown in Figure 6 - 11 respectively. From the MS data, the fragmentation pattern of SGR was depicted in Figure 12 and 13.

\section{Characterization of degradation products by UPLC MS/MS}

The degradation pattern of SGR in the mentioned conditions was interpreted from the mass data and tabulated in Table 8. From the data it is observed that a more degradants were formed during the peroxide stress. The synthetic schemes used by manufacturers

\begin{tabular}{|c|c|c|c|c|c|c|}
\hline $\begin{array}{l}\text { Recovery } \\
\text { level }\end{array}$ & $\begin{array}{c}\text { Test } \\
\text { concentration } \\
(\mu \mathrm{g} / \mathrm{mL})\end{array}$ & $\begin{array}{c}\text { Standard } \\
\text { concentration } \\
(\mu \mathrm{g} / \mathrm{mL})\end{array}$ & $\begin{array}{c}\text { Total } \\
\text { concentration } \\
(\mu \mathrm{g} / \mathrm{mL})\end{array}$ & $\begin{array}{l}\text { Peak intensity } \\
\quad(\mathrm{mAu})\end{array}$ & $\begin{array}{c}\text { Amount } \\
\text { founded (mg) }\end{array}$ & \% Recovery \\
\hline $50 \%$ & 100 & 50 & 150 & 327.16 & 157.78 & $105.18 \%$ \\
\hline $100 \%$ & 100 & 100 & 200 & 407.00 & 199.38 & $99.69 \%$ \\
\hline $150 \%$ & 100 & 150 & 250 & 496.90 & 249.73 & $99.89 \%$ \\
\hline
\end{tabular}



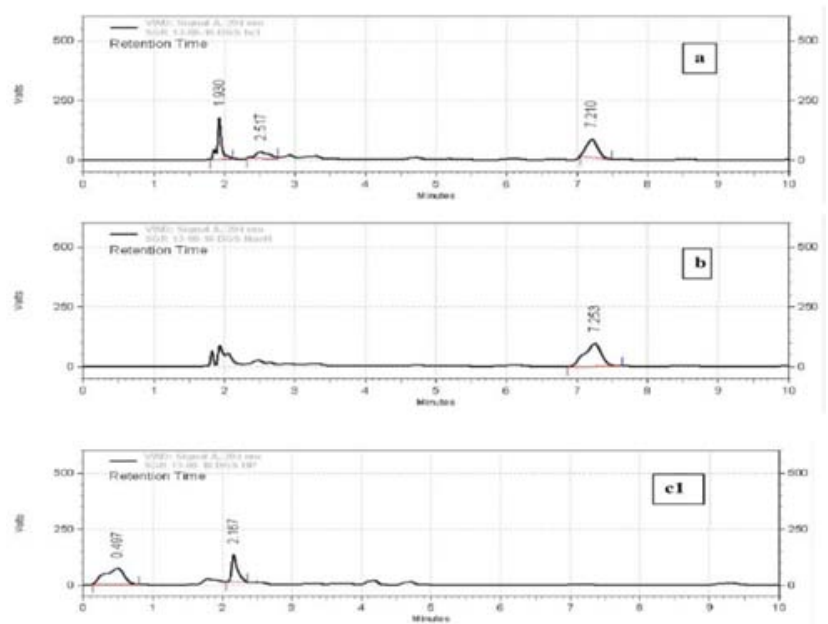

Figure 2: Typical HPLC chromatograms of saroglitazar and its degradation products formed. a) $0.1 \mathrm{~N} \mathrm{HCl}$, b) $0.1 \mathrm{~N} \mathrm{NaOH}, c 1$ ) $3 \%$ Hydrogen peroxide at $294 \mathrm{~nm}$.
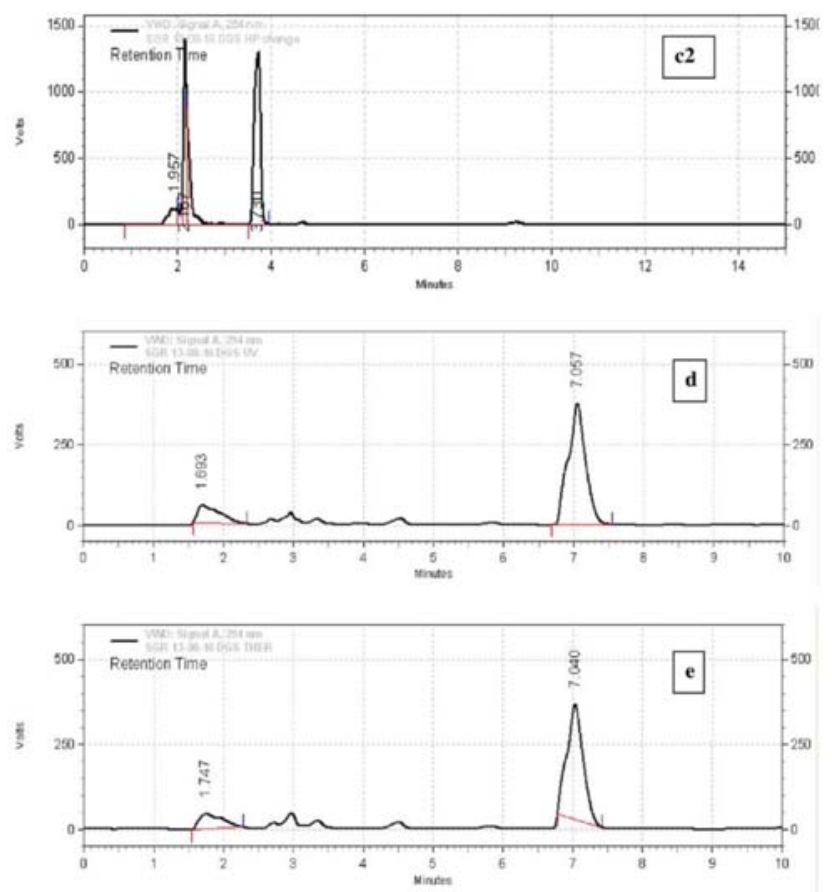

Figure 3: Typical HPLC chromatograms of saroglitazar and its degradation products formed. c2) $3 \%$ Hydrogen peroxide at $254 \mathrm{~nm}$ d) Photolysis UV light $365 \mathrm{~nm}$ and e) Thermal at $60^{\circ} \mathrm{C}$.

were observed for any starting reactants were formed during the degradation. The percentage degradation of SGR in presence of mentioned stress conditions was tabulated in Table 7 . The $\mathrm{m} / \mathrm{z}$ values at 247 and at 222 were corresponded to compound 4 and 14 which are one of the reactants during SGR synthesis. The products from acid stressed sample were found to possess molecular ion peaks at 325 and 238 which are correlated to compounds 1 and 2 . The base stress of SGR has shown the presence of two major degradants with $\mathrm{m} / \mathrm{z}$ at 365 and 247 depicted as 3 and 4 . With thermal stress, the
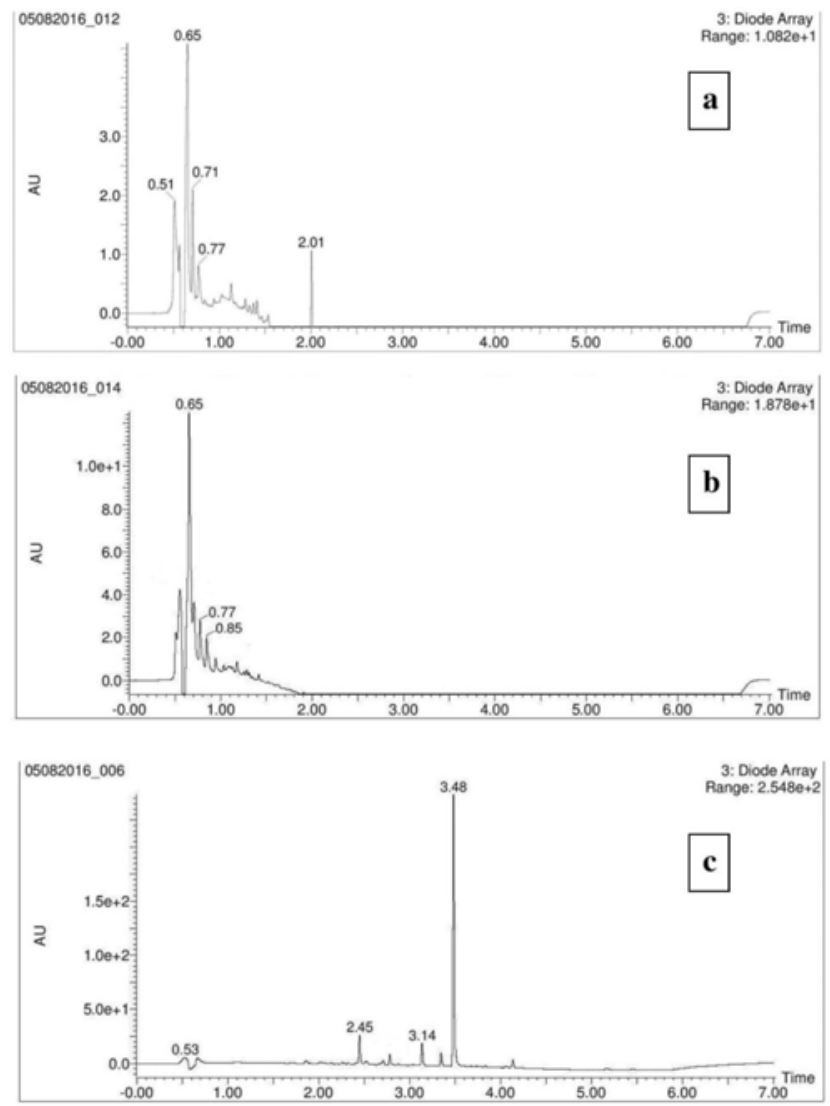

Figure 4: UPLC chromatograms of saroglitazar degradation products. a) Under acid stress b) Under base stress and c) Under thermal stress.
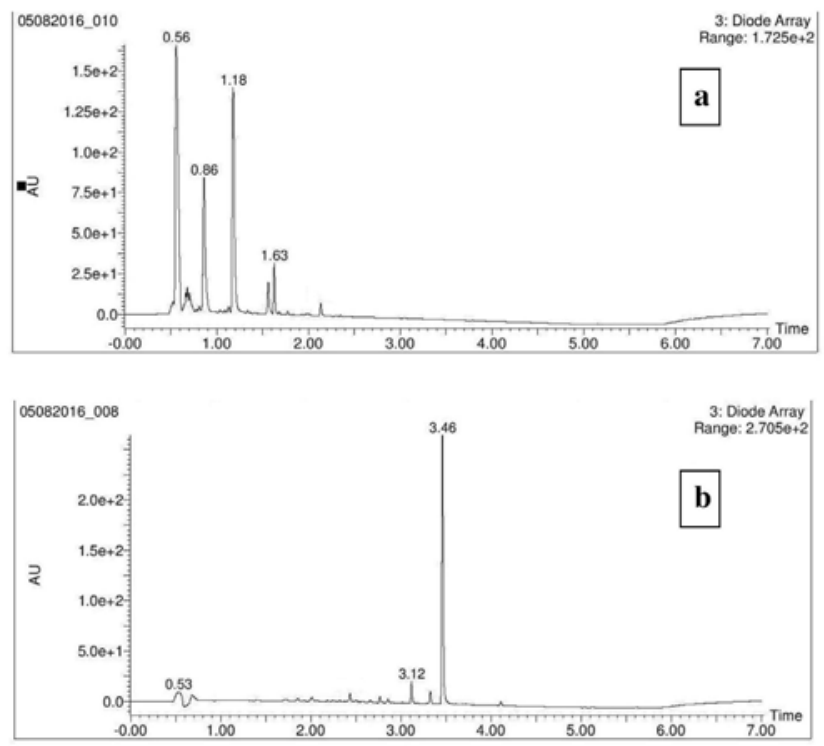

Figure 5: UPLC chromatograms of saroglitazar degradation products. a) Under peroxide stress and b) Under photolytic stress.

\begin{tabular}{|c|c|c|c|}
\hline \multicolumn{3}{|c|}{ Table 5: LOD and LOQ results of Saroglitazar. } \\
\hline $\begin{array}{c}\text { Calibration } \\
\text { Equation }\end{array}$ & $\begin{array}{c}\text { SD of lowest } \\
\text { concentration in } \\
\text { linearity }\end{array}$ & $\begin{array}{c}\text { LOD } \\
(\mu \mathrm{g} / \mathrm{mL})\end{array}$ & $\begin{array}{c}\mathrm{LOQ} \\
(\mu \mathrm{g} / \mathrm{mL})\end{array}$ \\
\hline $\mathrm{Y}=0.997 \mathrm{x}+4.500$ & 1.85538 & 1.7732 & 5.3735 \\
\hline
\end{tabular}




\begin{tabular}{|c|c|c|c|c|c|c|c|c|c|c|c|c|c|}
\hline \multirow{3}{*}{$\begin{array}{c}\text { Stress } \\
\text { condition }^{\#}\end{array}$} & \multirow{3}{*}{$\begin{array}{c}\lambda \\
(\mathrm{nm})\end{array}$} & \multicolumn{2}{|c|}{ Drug peak } & \multicolumn{10}{|c|}{ Degraded product peaks } \\
\hline & & \multirow[b]{2}{*}{$\mathbf{R t}^{*}$} & \multirow{2}{*}{$\begin{array}{l}\text { Peak } \\
\text { In** }\end{array}$} & \multicolumn{2}{|c|}{ Peak 1} & \multicolumn{2}{|c|}{ Peak 2} & \multicolumn{2}{|c|}{ Peak 3} & \multicolumn{2}{|c|}{ Peak 4} & \multicolumn{2}{|c|}{ Peak 5} \\
\hline & & & & $\mathbf{R t}^{*}$ & $\ln ^{* *}$ & $\mathbf{R t}^{*}$ & $\ln ^{* *}$ & $\mathbf{R t}^{*}$ & $\ln ^{* *}$ & $\mathbf{R t}^{*}$ & $\ln ^{* *}$ & $\mathbf{R t}^{*}$ & $\ln ^{* *}$ \\
\hline \multirow{2}{*}{$\begin{array}{c}\text { Acid } \\
(0.1 \mathrm{~N} \mathrm{HCl})\end{array}$} & 294 & 7.21 & 86.48 & 1.930 & 176.07 & - & - & - & - & - & - & - & - \\
\hline & 254 & - & - & - & - & - & - & - & - & - & - & - & - \\
\hline \multirow{2}{*}{$\begin{array}{c}\text { Base } \\
(0.1 \mathrm{~N} \\
\mathrm{NaOH})\end{array}$} & 294 & - & - & 1.830 & 66.05 & 1.940 & 86.293 & - & - & - & - & - & - \\
\hline & 254 & - & - & - & - & - & - & - & - & - & - & - & - \\
\hline \multirow{2}{*}{$\begin{array}{l}\text { Oxidative } \\
\left(3 \% \mathrm{H}_{2} \mathrm{O}_{2}\right)\end{array}$} & 294 & - & - & 0.496 & 74.77 & 2.167 & 135.50 & 4.17 & 20.42 & 4.70 & 13.36 & - & - \\
\hline & 254 & - & - & 2.166 & 1406.93 & 2.939 & 14.028 & 3.728 & 1302.5 & 4.67 & 19.61 & 9.257 & 19.36 \\
\hline \multirow{2}{*}{$\begin{array}{l}\text { Light } \\
\text { (UV) }\end{array}$} & 294 & 7.05 & 377.68 & 1.699 & 62.16 & 2.962 & 39.139 & 3.327 & 19.322 & 4.54 & 20.59 & - & - \\
\hline & 254 & - & - & - & - & - & - & - & - & - & - & - & - \\
\hline \multirow{2}{*}{$\begin{array}{c}\text { Thermal } \\
\left(60^{\circ} \mathrm{C}\right)\end{array}$} & 294 & 7.03 & 368.10 & 1.747 & 44.547 & 2.721 & 19.183 & 2.964 & 46.839 & 3.34 & 24.85 & 4.507 & 20.5 \\
\hline & 254 & - & - & - & - & - & - & - & - & - & - & - & - \\
\hline
\end{tabular}

\# 48 hours, *Retention time (minutes), **Intensity (mAu), (-) indicates, absence of peaks.

\begin{tabular}{|c|c|c|}
\hline \multicolumn{3}{|c|}{ Table 7: Percentage of SGR degradation. } \\
\hline Stressed condition & Duration (hr) & \% Degradation \\
\hline Acid Hydrolysis & 48 & $85.18 \%$ \\
\hline Basic Hydrolysis & 48 & $71.95 \%$ \\
\hline Oxidation & 48 & $100 \%$ \\
\hline Photolytic & 48 & $1.28 \%$ \\
\hline Thermal & 48 & $5.69 \%$ \\
\hline
\end{tabular}



Figure 7: MS/MS-ESI data of saroglitazar degradation products under base stress.



Figure 6: MS/MS-ESI data of saroglitazar degradation products under acid stress.



Figure 8: MS/MS-ESI data of saroglitazar degradation products under hydrogen peroxide stress. 


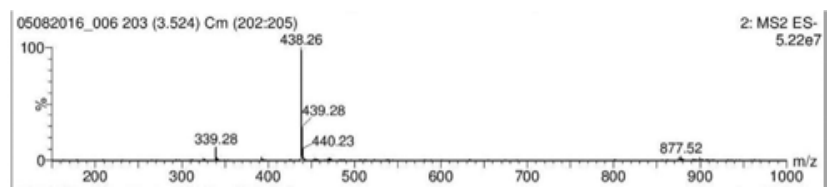

Figure 9: MS/MS-ESI data of saroglitazar degradation products under thermal stress.

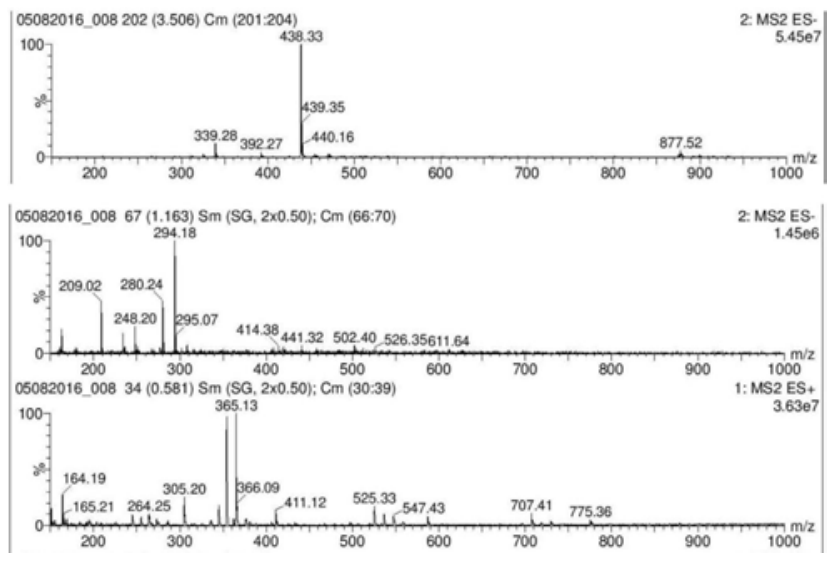

Figure 10: MS/MS-ESI data of saroglitazar degradation products under photolytic stress.

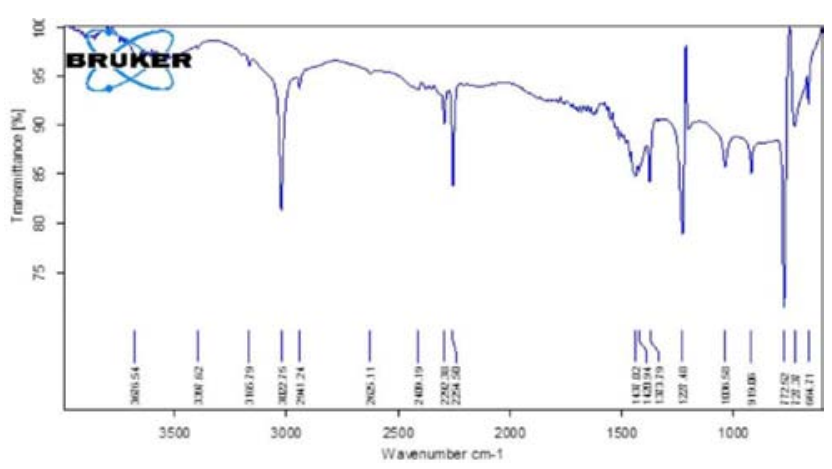

Figure 11: FTIR NaCl liquid sample spectra of degradation products of saroglitazar.

drug has shown $\mathrm{m} / \mathrm{z}$ at 354 and 381 correlated to compound 8 and 9 respectively. The photolytic stress has shared its degradation products 6 and 7 in similarity with both thermal and base stress respectively. A major peak at $\mathrm{m} / \mathrm{z} 294$ is observed in photolytic stress corresponds to compound 5 . Compounds 3 , 7, and 10 are same, indicting common feature of peroxide and base stress. Similar feature was observed for compound 4 and 12. From this study it is observed that peroxide and base conditions are generating a common degradant, which is a starting reactant during SGR synthesis. ${ }^{16}$ In thermal stress, minor products 8 and 9 were observed. The SGR sample was much degraded in presence of hydrogen peroxide, indicating that, the drug is highly unstable in peroxide or oxygen atmosphere. The major compounds obtained are 10 and16 with Rt of 1.380 and

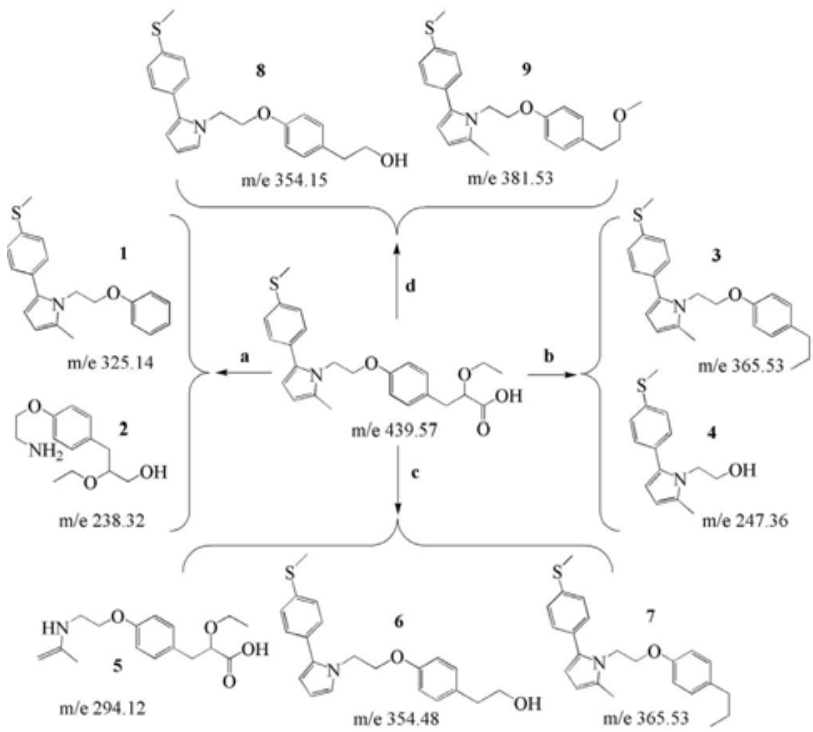

Reagents and Conditions: a. Acid degradation, $0.1 \mathrm{~N} \mathrm{HCl}, 48$ hours with stirring. b. Base degradation, $0.1 \mathrm{~N} \mathrm{NaOH}, 48$ hours with stirring. c. Photolytic degradation, U.V. light exposure, 48 hours. d. Thermal degradation, $60^{\circ} \mathrm{C}, 48$ hours.

Figure 12: Depiction of saroglitazar degradation products under acid, base, thermal and U.V. stress.

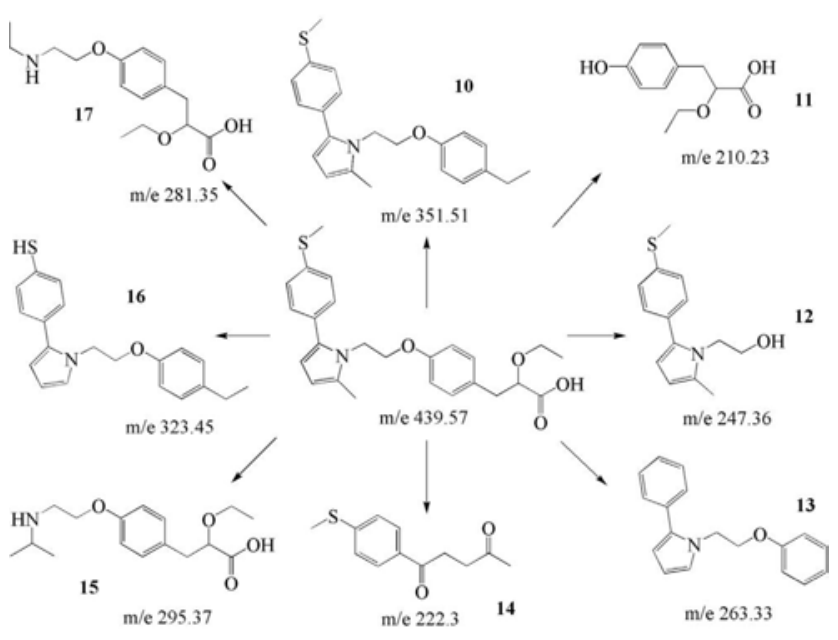

Reagents and conditions: Hydrogen peroxide ( $3 \%)$, stirring, 48 hours

Figure 13: Depiction of saroglitazar degradation products under peroxide stress.

0.902 minutes respectively. The Rt of degradant compounds shows that they are having high polarity than the parent compound SGR (see Table 6). Compound 17 obtained from peroxide stress having an Rt of $0.86 \mathrm{~min}$, is one of the reactant during SGR synthesis. The IUPAC names of the degradant compounds identified were tabulated in Table 8 .

\section{Characterization of degradation products by FTIR}

The FTIR spectrum $\left(\mathrm{NaCl}, \mathrm{cm}^{-1}\right)$ for eluted peak of peroxide stressed sample from HPLC was shown in Figure 11. The vibrations were observed at $3545.44(\mathrm{~N}-\mathrm{H}$ 
Table 8: Degradants observed from LCMS/MS data.

\begin{tabular}{|c|c|}
\hline Degradant Code & IUPAC Name of Degradants obtained from stability studies \\
\hline 1 & 2-methyl-5-(4-(methylthio)phenyl)-1-(2-phenoxyethyl)-1H-pyrrole \\
\hline 2 & 3-(4-(2-aminoethoxy)phenyl)-2-ethoxypropan-1-ol \\
\hline $3,7,10$ & 1-(2-(4-propylphenoxy)ethyl)-2-methyl-5-(4-(methylthio)phenyl)-1H-pyrrole \\
\hline 4,12 & 2-(2-methyl-5-(4-(methylthio)phenyl)-1H-pyrrol-1-yl)ethanol \\
\hline 5,15 & 3-(4-(2-(prop-1-en-2-ylamino)ethoxy)phenyl)-2-ethoxypropanoic acid \\
\hline 6,8 & 2-(4-(2-(2-(4-(methylthio)phenyl)-1H-pyrrol-1-yl)ethoxy)phenyl)ethanol \\
\hline 9 & 1-(2-(4-(2-methoxyethyl)phenoxy)ethyl)-2-methyl-5-(4-(methylthio)phenyl)-1H-pyrrole \\
\hline 11 & 2-ethoxy-3-(4-hydroxyphenyl)propanoic acid \\
\hline 13 & 1-(2-phenoxyethyl)-2-phenyl-1H-pyrrole \\
\hline 14 & 1-(4-(methylthio)phenyl)pentane-1,4-dione \\
\hline 16 & 4-(1-(2-(4-ethylphenoxy)ethyl)-1H-pyrrol-2-yl)benzenethiol \\
\hline 17 & 3-(4-(2-(ethylamino)ethoxy)phenyl)-2-ethoxypropanoic acid \\
\hline
\end{tabular}

stretching), 3021.95 (C-H Stretching), 2292.69, 2253.42 ( $\mathrm{C}=\mathrm{C}$ stretching), 1627.05 ( $\mathrm{C}=\mathrm{O}$ stretching), 1442.37 (C-H bending), 1375.27 (N-H asymmetric bending), 1228.74 (C-O-C stretching), 1008.19 (C-O-C asymmetric stretching), 918.86 (O-H bending in finger print region), 761.61 (Aromatic region in finger print). From the data it was observed that the compound 17 was present. A similar stretching vibrations were observed as 2544.44 (S-H stretching), 3025.15 to 2944.92 (C-H Stretching), 2253.42 ( $\mathrm{C}=\mathrm{C}$ stretching), 1442.37 ( $\mathrm{C}-\mathrm{H}$ bending), 1313.37 (C-N asymmetric bending), 1228.74 (C-O-C stretching), 1008.19 (C-O-C asymmetric stretching), 761.61 (Aromatic region in finger print). From the data it was observed that the compound $\mathbf{3}$ was present. Thus the retrieved portions of eluted peaks gave a functional group analysis in correlating the spectra.

\section{CONCLUSION}

From the study it is observed that, the drug SGR is having stability under photo and thermal stress but sensitive to other conditions. The effect of peroxides on drug is vast, indicating that it should be stored away from oxidation during its storage and transport. The degradants obtained during oxidation are easily identified at $254 \mathrm{~nm}$. The structural interpretation of degraded products shows that the SGR is degrading back into its reactants used during its synthesis. Since the oral hypoglycemic drugs are in high usage, a further in vivo metabolite correlation is needed to identify the toxicity of degradants.

\section{CONFLICT OF INTEREST}

The authors have no conflict of interest.

\section{ACKNOWLEDGEMENT}

The authors are thankful for Chebrolu Hanumaiah Institute of Pharmaceutical Sciences for providing the facilities. The authors are thankful for Council for Scientific and Industrial Research and Indian Institute of Integrated Medicine, Mumbai for helping in LCMS studies.

\section{ABBREVIATIONS}

SGR: Saroglitazar; LCMS: Liquid Chromatography Mass Spectroscopy; FTIR: Fourier Transform Infrared; RP-HPLC: Reverse Phase High Performance Liquid Chromatography.

\section{REFERENCES}

1. Aggarwal A. Saroglitazar: India's answer to diabetic dyslipidemia. Int J Pharmacol Clin Sci. 2014;3:7-14.

2. Aggarwal R. The First Approved Agent in the Glitazar's Class: Saroglitazar. Ingenta connect, Curr. Drug Targ. 2014;15(2):151-5.

3. Anirban M. Sanjay Chatterjee. Diabetic Dyslipidemia - Role of Saroglitazar. Med Chem. 2014;4:684-7.

4. Sosale A, Saboo B, Sosale B. Saroglitazar for the treatment of hypertriglyceridemia in patients with type 2 diabetes: Current evidence. Dove Press: Sci Med Res. 2015;8:189-96.

5. Jani RH, Kansagra K, Jain MR, Patel H. Pharmacokinetics, Safety and Tolerability of saroglitazar (ZYH1), a Predominently PPARa agonist with moderate PPARY agonist activity in healthy human subjects. Clin Drug Invest. 2013;33(11):809-16.

6. Chatterjee S, Majumder A, Ray S. Observational Study of Effects of Saroglitazar on Glycaemic and Lipid Parameters on Indian Patients with Type 2 Diabetes. Sci Rep. 2015;5:7706.

7. Shetty SR, Kumar S, Mathur RP, Sharma KH, Jaiswal AD. Observational study to evaluate the safety and efficacy of saroglitazar in Indian diabetic dyslipidemia patients. Ind Heart J. 2015;67(1):23-6.

8. Subramanian S, Krishnan R. From 'Make in India' to 'Made in India': The saroglitazar story, Ind Heart J. 2015;67(1):8-10.

9. Srinivas PM, Harinarayan CV. Role of Glitazars in atherogenic dyslipidemia and diabetes: Two birds with single stone. Ind J Endocrinol Metabol. 2014;18(3):283-7.

10. Brenna E. "Enzyme-mediated synthesis of EEHP and EMHP, useful pharmaceutical intermediates of PPAR agonists". Tetrahedron: Asymm. 2009;20(22):2594-9.

11. Hanumantharao K, Lakshmanarao A, Chandra KB. Method development and validation of Saroglitazar in bulk and Pharmaceutical dosage form by RP-HPLC, Ind. J Pharm Pharmacol. 2015;2(3):150-4. 

HPTLC method for the estimation of saroglitazar in bulk and Pharmaceutical dosage form Austin. J Anal Pharm Chem. 2015;2:1-4

13. Ganesh, Kumar TN, Vidyadhara S, Niteen A, Narkhede Y, SaiShilpi M, Rajya Lakshmi. Method development, validation, and stability studies of Teneligliptin by RPHPLC and identification of degradation products by UPLC Tandem mass spectroscopy. J Anal Sci Tech. 2016;7(1):27.
14. $\mathrm{ICH}$ harmonized tripartite guidelines, validation of analytical procedure and methodology, Q2B. 1996;4:1-8.

15. $\mathrm{ICH}, \mathrm{Q} 2(\mathrm{R} 1)$, Validation of analytical procedures: Text and methodology. 2005.

16. Braj Bhushan L, Vidya Bhushan L, Vijay Kumar B, Saurin KR, Preeti SR, Sujay B. Novel pyrroles having hypolipidemic hypocholesteremic activities, process for their preparation and pharmaceutical compositions containing them and their use in medicine, WIPO patent: WO2003009841 A1. 2003.

\section{PICTORIAL ABSTRACT}



\section{About Authors}

\section{SUMMARY}

- Saroglitazar is a recently FDA approved oral hypoglycemic drug used for treating Diabetes mellitus. Its use has been increasing among people day by day. Hence to observe any stability issues, the drug degradation conditions are studied as per $\mathrm{ICH}$ guidelines of stability testing.

- The drug has shown much degradation in presence of oxidation environment. It has high stability in presence of thermal and sunlight presence. Thus its storage is to be properly packed to avoid changed $\mathrm{pH}$ and oxygen containing surroundings during its transport and storage. A caution should be labeled on formulations.

- Major degradant products were identified and characterized by LCMS/MS and FTIR techniques. The toxicity profile of the identified products during stress are to be studied further for better safety of humans.

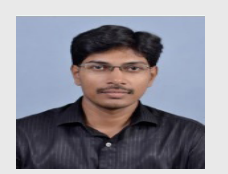

T N V Ganesh Kumar: Associate Professor at Chebrolu Hanumaiah Institute of Pharmaceutical Sciences, Guntur. His area of interest is drug metabolism and pharmacokinetic studies. He is working on characterization of drug metabolites by LCMS, NMR studies and their toxicity profiles.

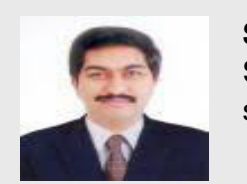

S. Vidyadhara: Professor and Principal, at Chebrolu Hanumaiah Institute of Pharmaceutical Sciences, Guntur. His area of specialization is Novel Drug Delivery, Nano formulation studies and solid dispersions. He is also working in Chromatography studies and their validations.



Niteen A Narkhede: Working at CSIR, Mumbai. His area of interest is Method development and validation of drug products by LCMS.

Yamini Sai Silpa: Post Graduate Student at Chebrolu Hanumaiah Institute of Pharmaceutical Sciences, Guntur. She is working on determining the toxicity profiles of drugs.

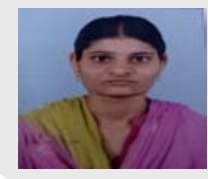

Rajya Lakshmi:Post Graduate Student at Chebrolu Hanumaiah Institute of Pharmaceutical Sciences, Guntur. She is working on HPLC method development.

Cite this article: Kumar TNVG, Vidyadhara S, Narkhede NA, Silpa NY, Lakshmi MR. Identification of Degradant Products of Saroglitazar by UPLC Tandem Mass Spectroscopy and Attenuated Total Reflection FTIR Techniques. Indian J of Pharmaceutical Education and Research. 2018;52(4):635-43. 